Canadian

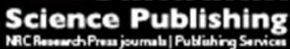

Applied Physiology, Nutrition, and Metabolism Physiologie appliquée, nutrition et métabolisme

Isometric and dynamic strength and neuromuscular attributes as predictors of vertical jump performance in 1113 year-old male athletes

\begin{tabular}{|r|l|}
\hline Journal: & Applied Physiology, Nutrition, and Metabolism \\
\hline Manuscript ID & apnm-2017-0111.R1 \\
\hline Manuscript Type: & Article \\
\hline Complete List of Authors: & $\begin{array}{l}\text { McKinlay, Brandon; Brock University, Applied Health Sciences } \\
\text { Wallace, Phillip; Brock University, Department of Kinesiology, Centre for } \\
\text { Bone and Muscle Health } \\
\text { Dotan, Raffy; Brock University, Faculty of Applied Health Sciences } \\
\text { Long, Devon; Brock University, Applied Health Sciences } \\
\text { Tokuno, Craig; Brock University, Kinesiology } \\
\text { Gabriel, David; Brock University, } \\
\text { Falk, Bareket; Brock University, }\end{array}$ \\
\hline Is the invited manuscript for \\
consideration in a Special \\
Issue? :
\end{tabular}




\section{Isometric and dynamic strength and neuromuscular attributes as predictors of vertical jump performance in 11-13 year-old male athletes}

Brandon John McKinlay, Phillip J. Wallace, Raffy Dotan, Devon Long, Craig Tokuno, David A. Gabriel, Bareket Falk

Faculty of Applied Health Sciences, Brock University, St Catharines, ON, Canada, L2S 3A1 Applied Physiology Laboratory, Centre for Bone and Muscle Health

\section{Corresponding author}

\section{Bareket Falk}

Department of Kinesiology, Centre for Bone and Muscle Health

Faculty of Applied Health Sciences

Brock University

1812 Sir Isaac Brock Way

St Catharines, ON, Canada, L2S 3A1

Email: bfalk@brocku.ca

Tel: 905-688-5550, ext 4979 


\begin{abstract}
In explosive contractions, neural activation is a major factor in determining the rate of torque development, while the latter is an important determinant of jump performance. However, the contribution of neuromuscular activation and rate of torque development to jump performance in children and youth is unclear. PURPOSE: To examine the relationships between the rate of neuromuscular activation, peak torque, rate of torque development, and jump performance in

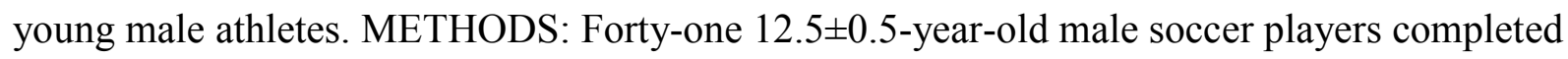
explosive, unilateral isometric and dynamic (240\%) knee extensions (Biodex System III), as well as counter-movement-, squat-, and drop-jumps. Peak torque (pT), peak rate of torque development (pRTD) and rate of vastus lateralis activation $\left(\mathrm{Q}_{30}\right)$ during the isometric and dynamic contractions were examined in relation to attained jump heights. RESULTS: Isometric $\mathrm{pT}$ and $\mathrm{pRTD}$ were strongly correlated $(\mathrm{r}=0.71)$ but not related to jump performance. Dynamic pT and pRTD, normalized to body mass, were significantly related to jump height in all three jumps $(\mathrm{r}=0.38-0.66, \mathrm{p}<0.05)$. Dynamic normalized, but not absolute $\mathrm{pRTD}$, was significantly related to $\mathrm{Q}_{30}(\mathrm{r}=0.35, \mathrm{p}<0.05)$. CONCLUSION: In young soccer players, neuromuscular activation and rate of torque development in dynamic contractions are related to jump performance, while isometric contractions are not. These findings have implications in the choice of training and assessment methods for young athletes.
\end{abstract}

Key words: Child; EMG; Exercise; Muscle; Sport; Strength 


\section{INTRODUCTION}

Vertical jump ability is an important performance indicator, used in many competitive sports (Gore 2000). It is largely taken to reflect muscles' explosive contractile capacity and is thus, also indirectly associated with other explosive, non-jumping activities, e.g., sprinting and kicking (Kraska et al. 2009; Peterson et al. 2006). Therefore, understanding the underlying factors contributing to jumping ability could be beneficial for improving sport performance involving jumping and other athletic activities.

Isometric explosiveness, or the rate of torque development (RTD) in isometric contractions, has been examined in relation to jump performance in adults, with inconsistent results. While several studies reported significant correlations between jump performance and knee-extensor RTD (de Ruiter et al. 2010; de Ruiter et al. 2006; Paasuke et al. 2001; Thompson et al. 2013), others did not (Baker et al. 1994; McGuigan and Winchester 2008). This inconsistency may be due to methodological differences between studies, such as different testing modalities, contraction types, or joint angles, or to different populations (e.g., athletes and non-athletes). For example, de Ruiter et al. (2006) reported a correlation between the early rise of isometric torque and jump height in recreational athletes, but not in competitive volleyball players (de Ruiter et al. 2007). Additionally, Nuzzo et al. (Nuzzo et al. 2008) demonstrated that measures of strength (force) in dynamic, multi-joint contractions are more closely related to jump height than the corresponding isometric measures. Despite this inconsistency, it is widely accepted that explosive strength, as quantified under laboratory conditions, is positively related to explosive actions, such as jumping, and to sports performance, in general (Wilson and Murphy 1996).

Explosiveness, or peak RTD (pRTD), is related to the rate of muscle activation, as reflected by the early rise in electromyographic (EMG) activity just prior to contraction onset (de 
Ruiter et al. 2004; de Ruiter et al. 2006). However, the latter is not always found closely related to jump performance. For example, in adults, de Ruiter et al. (de Ruiter et al. 2007) observed a strong relationship between jump height and evoked pRTD of the knee extensors. However, the associated early rise in EMG was not related to jump height.

To the authors' knowledge, the relationship between jump performance, isometric or dynamic explosive strength, and its associated neuromuscular variables, has not been examined in children or adolescents. Compared with adults, children are characterized by lower muscular strength and power (Blimkie 1989; Sale 1996) and lower rates of the associated early EMG rise (Cohen et al. 2010; Falk et al. 2009; Waugh et al. 2013). In isometric contractions, Mitchell et al. (Mitchell et al. 2011) demonstrated greater early EMG rise in 7-12-yr-old male gymnasts, compared with non-athletes. However, jump performance was not examined. Recently, it was suggested that children utilize their higher-threshold motor units to a lesser extent than adults (Dotan et al. 2012), which may explain their lower explosive strength. Therefore, the relationships between explosive strength, muscle activation, and jump performance amongst youth may be different than that seen in adults. Also, it is unknown how these relationships differ in isometric vs. dynamic contractions. In view of the above-mentioned child-adult differences, it is important to gain an understanding in this area.

Therefore, the purpose of this study was to: 1 . Investigate the relationship between the rate of knee extensor activation (as reflected by the rate of early EMG rise) and pRTD during isometric and dynamic contractions; and 2. Examine the extent to which maximal torque, pRTD, and rate of early EMG rise are related to vertical jump performance in young male athletes. It was hypothesized that both maximal isometric and dynamic RTDs, as well as their respective early muscle activation will be related to jump height. 


\section{METHODS}

\section{Experimental Approach}

Competitive young male soccer players were tested for static and dynamic strength, explosive strength, and the rate of muscle activation. In addition, three types of jump performance (countermovement jump, CMJ; squat jump, SJ; and drop jump, DJ) were assessed. This correlational study examined the relationships between jump capacity and the laboratory-based strength and neuromuscular variables.

\section{Participants}

Participants were forty-one high-level, $12.5 \pm 0.5$ year-old male competitive soccer players. Their physical characteristics and training history are shown in Table 1 . They were all recruited from local soccer clubs. As competitive athletes, the participants were familiar with maximal exertions.

\section{[ Table 1 ]}

The study was cleared by the institutional Research Ethics Board. A thorough explanation of the study's purpose, procedures, benefits and potential risks or discomforts were given to all participants and, as applicable, to their parents/guardians. All signed informed assent or consent forms prior to testing commencement.

\section{Procedures}

Participants' strength, neuromuscular attributes and jumping ability were assessed in two separate sessions. All strength and neuromuscular testing was performed in the laboratory. 
Following familiarization to all procedures, tests were administered in the following order: anthropometric measurements, followed by isometric- and then dynamic-strength testing. All jump tests were performed on another day at the boys' soccer training facility in the following order: CMJ, DJ, and SJ.

\section{Measurements}

\section{Anthropometry, body composition, and maturity}

Height and sitting height were measured using a stadiometer (Ellard Instrumentation, Ltd., Monroe, WA) and recorded to the nearest $1 \mathrm{~mm}$. Body-fat percentage, recorded to the nearest 0.1\%, was estimated using bioelectrical impedance analysis (InBody520, Biospace Co. Ltd.), which has previously been validated in children and adolescents (Kriemler et al. 2009). The digital scale of the InBody520 was used to measure body mass, recorded to the nearest $0.1 \mathrm{~kg}$. To eliminate inter-observer variability, all anthropometric measurements were performed by the same investigator.

Maturity was assessed by calculating the maturity offset relative to predicted age of peak height-velocity (PHV), as described by Mirwald et al. (Mirwald et al. 2002) (based on age, weight, height, and sitting height). Additional classification was based on self-determined secondary sexual characteristics, as described by Tanner (Tanner 1962) (the boys were provided with drawings of the different pubertal stages of pubic hair development and asked to mark the most applicable one).

\section{Muscle Strength}

All isometric and dynamic strength measurements were performed on the right leg, using a Biodex System III dynamometer (Biodex, Shirley, NY). All participants were right-leg dominant. The participants were seated in the dynamometer's chair and stabilized using a cross-hip strap and 
two diagonal, cross-chest shoulder straps. The dynamometer lever-arm contact pad was adjusted to $\sim 3 \mathrm{~cm}$ above the lateral malleolus via an ankle strap. The lever's axis of rotation was aligned with the knee's axis (femur's lateral condyle). The knee was then set at a $90^{\circ}$ starting position $\left(180^{\circ}=\right.$ full extension $)$

Once the participant was properly seated and secured, a familiarization and warm-up protocol was initiated for both the dynamic and isometric forms of testing. The familiarization protocol consisted of three $180 \%$ s isokinetic (dynamic) contractions and three submaximal isometric contractions, followed by two maximal $240^{\circ} / \mathrm{s}$ dynamic and two maximal isometric contractions. If a participant did not feel comfortable with the movement or the protocol, or exhibited performance inconsistency by the end of the familiarization sets, additional trials were administered.

The subsequent testing consisted of five 3-s maximal isometric knee extensions at $90^{\circ}$, followed by five maximal dynamic contractions at $240 \%$ s. Contractions were separated by a minimum of 30-s rest between repetitions and 5-min rest between contraction-types.

Prior to each contraction, participants were instructed to "kick out as fast and then as hard as possible" from a completely relaxed state. Verbal encouragement was given, along with visual torque-level feedback on the Biodex monitor. Torque and EMG signals were recorded prior to and throughout each contraction. Additional repetitions were performed when contractions were visually deemed improper due to execution errors (e.g., preceding countermovement of the leg), baseline instability, or abnormalities in the torque or EMG traces. All dynamometer measurements were performed by the same investigator.

\section{Electrode placement}


EMG was recorded from the right vastus lateralis using a bipolar surface electrode configuration (Delsys 2,1, Delsys Inc., Boston, MA). Electrode skin-sites were cleaned with isopropyl alcohol and abrasive gel (Nuprep, Weaver and Co., Aurora, CO, USA). Electrodes were placed on the muscle belly, parallel to fibre direction, using Delsys's proprietary double-sided adhesive interface tape. Exact placement was determined by manual palpation and visual inspection during a resisted isometric contraction in accordance with the Surface Electromyography for the Non-Invasive Assessment of Muscles (SENIAM) group recommendations for the vastus lateralis. A reference/ground electrode was placed over the C-7 vertebral prominence.

\section{EMG and torque data acquisition}

All channels were sampled at $1000 \mathrm{~Hz}$, using a computer-based oscillograph and data acquisition system (EMGworks). EMG signals were band-pass Butterworth filtered (20-450 Hz), using the Bagnoli-4 bioamplifier (Delsys Inc., Boston, MA). Position and torque signals from the Biodex were sent to a 16-bit A/D converter (BNC-2110, National Instruments) and smoothed using a 6-Hz low-pass, 2nd-order Butterworth filter. Recorded data were stored and subsequently analysed using MATLAB (The MathWorks, Natick, MA).

\section{Selection of Best Trials}

All isometric and dynamic knee-extension trials were ranked by their pT and pRTD. Both variables were expressed as a percentage of the respective maximal value, obtained in the five trials. For each trial, the product of the percentage value of $\mathrm{pT}$ and $\mathrm{pRTD}$ was calculated to provide a composite score for that trial. Trials were then ranked from 1 to 5 . The two highestranked trials were used for further analysis, provided both $\mathrm{pT}$ and $\mathrm{pRTD}$ were above $80 \%$ of their 
respective maxima. Two-trial averages of all measured variables were calculated for subsequent analysis.

\section{Muscle Force Variables}

pT was defined as the peak torque developed during a maximal voluntary contraction. Values were recorded from the dynamometer's torque signal rather than from the dynamometer's processed display and are presented as absolute values $(\mathrm{Nm})$, and body-mass-corrected values $\left(\mathrm{Nm} \cdot \mathrm{kg}^{-1}\right)$.

$\mathrm{pRTD}$ (peak $\Delta$ torque/ $\Delta$ time ratio) (Aagaard et al. 2002) was determined as the peak of the first derivative of the torque trace. pRTD is presented in absolute values $\left(\mathrm{Nm} \cdot \mathrm{s}^{-1}\right)$ and body-mass corrected values $\left(\mathrm{Nm} \cdot \mathrm{kg}^{-1} \cdot \mathrm{s}^{-1}\right)$.

\section{EMG Variables}

All EMG variables were analyzed from the rectified linear envelope of the filtered trace. The onset of muscle activation was defined as the point at which the EMG signal rose two standard deviations above the mean amplitude of baseline-activity in the initial 500ms and remained elevated for at least 100ms (Hodges and Bui 1996).

\section{Rate of muscle activation}

The rate of muscle activation was defined as the area under the rectified linear envelope of the EMG signal (Gabriel and Boucher 2000) and was calculated for the first $30 \mathrm{~ms}\left(\mathrm{Q}_{30}\right)$.

\section{Performance Testing}

Maximal jump height was assessed for the three jump types (CMJ, SJ, DJ), using the Optojump photoelectric system (Microgate, Bolzano, Italy). Participants were familiarized with all jumps prior to testing and then performed each jump type three times at maximal effort, with 
2-min rest intervals. The best trial, defined by the maximal height achieved, was used for further analysis.

Participants received explanation and feedback on proper execution for each jump and were instructed to "jump as high as possible, as if trying to touch the ceiling". Additionally, participants were instructed not to 'tuck' or 'bend' their knees during the flight stage of the jump.

CMJ was performed from the upright position with a subsequent downward movement before push-off. Arm swing was permitted (Bobbert et al. 1996). SJ was performed from a semisquat position (knee angle $\sim 90^{\circ}$ ), with no counter-movement and no arm swing (Bobbert et al. 1996). DJ was performed by stepping off a 20-cm-high platform and, upon landing, immediately

jumping vertically as high as possibly (Bobbert et al. 1987). Hands were placed on the waist and no arm swing was permitted.

The Optojump system has been shown to be a valid and reliable means for calculating vertical jump height (Glatthorn et al. 2011), based on airborne time(s), using the formula: Jump Height $=9.81 \times(\text { airborne time })^{2} / 8$.

\section{Statistical Analyses}

All statistical analyses were performed using SPSS v.20 (SPSS Inc., Chicago, IL). The data are presented as mean \pm 1 standard deviation. Pearson product-moment correlation coefficients (r) were used to evaluate the relationships between variables. Statistical significance was defined as $\mathrm{p}<0.05$. A stepwise linear regression model was used to determine the extent to which independent variables (i.e., body mass, maturity, muscle strength) explained the observed variance in jumping ability. 


\section{RESULTS}

Isometric and dynamic $\mathrm{pT}$ and $\mathrm{pRTD}$ values are presented in Table 2 . The attained jump height was $30.7 \pm 4.3 \mathrm{~cm}$ for the counter-movement jump, $30.2 \pm 5.1 \mathrm{~cm}$ for the drop jump, and $25.2 \pm 4.7 \mathrm{~cm}$ for the squat jump.

\section{[ Table 2 ]}

Age was significantly correlated with isometric and dynamic pRTD ( $\mathrm{r}=0.31$ and 0.37 , respectively, $\mathrm{p}<0.05$ ) but not with $\mathrm{pT}$. Maturity offset (years to PHV) was significantly correlated with both, isometric and dynamic $\mathrm{pT}(\mathrm{r}=0.52,0.54 ; \mathrm{p}<0.001$, respectively) and with isometric and dynamic $\mathrm{pRTD}(\mathrm{r}=0.55,0.46 ; \mathrm{p}<0.001$, respectively).

Absolute $\mathrm{pT}$ and $\mathrm{pRTD}$ were significantly inter-correlated in both the isometric $(\mathrm{r}=0.71$; $\mathrm{p}=0.0001)$ and dynamic contractions $(\mathrm{r}=0.89 ; \mathrm{p}<0.0001)$. Isometric $\mathrm{pT}$ was significantly related to dynamic $\mathrm{pT}$, whether expressed in absolute values or normalized to body mass $(\mathrm{r}=0.76$ and 0.40 , respectively; $\mathrm{p}<0.01$ ). Likewise, isometric $\mathrm{pRTD}$ was significantly related to dynamic $\mathrm{pRTD}$, whether expressed in absolute values or relative to body mass ( $\mathrm{r}=0.82$ and 0.64 , respectively; $\mathrm{p}<0.001)$.

The correlations between strength measures and jump performances appear in Table 3 . Isometric $\mathrm{pT}$ and $\mathrm{pRTD}$ were not related to jump performance, whether expressed in absolute or normalized terms. Absolute dynamic $\mathrm{pT}$ and $\mathrm{pRTD}$ were significantly related to performance in the CMJ, but not in SJ or DJ. When normalized to body mass, dynamic pT and pRTD were significantly related to performance in all three jumps (Figure 1). $\mathrm{Q}_{30}$ in the dynamic but not the isometric contraction was significantly related to jump performance in the $\mathrm{SJ}$ and $\mathrm{DJ}(\mathrm{r}=0.34$ and 0.31 , respectively; $\mathrm{p}<0.05)$. 


\section{[ Table 3 ]}

\section{[ Figure 1 ]}

Both absolute isometric and dynamic pRTDs were not related to $\mathrm{Q}_{30}$. However, when normalized to body mass, dynamic (but not isometric) pRTD contraction was significantly correlated with $\mathrm{Q}_{30}(\mathrm{r}=0.35$, Figure 2$)$. When $\mathrm{Q}_{30}$ was normalized to peak EMG amplitude, no correlations were observed with body-mass-normalized $\mathrm{pT}$ or $\mathrm{pRTD}$.

\section{[ Figure 2 ]}

Results of the linear-regression analysis of the factors contributing to jump performances are presented in Table 4 . Combined variables accounted for 44,32 , and $24 \%$ of the observed variance in CMJ, SJ, and DJ jump height, respectively. Importantly, the same two variables, absolute dynamic pT and body mass, were consistently found to significantly account for the variance observed in all three jump types. Maturity offset (years to peak height velocity), $\mathrm{Q}_{30}$, and pRTD did not enter the regression model.

\section{[ Table 4 ]}

\section{DISCUSSION}

Several important findings stem from the present study. First, dynamic, body-massnormalized pT and pRTD were significantly correlated with all three jump types, while isometric pT and pRTD did not. Absolute dynamic pT and pRTD significantly correlated with jump height only in CMJ. Body-mass dependency was expected since, in all jump types, it is the body's mass rather than an external object that is accelerated against gravity. The finding that dynamic $\mathrm{pT}$ and pRTD correlated with jumping performance much better than their isometric counterparts (Table 
3 ) is in agreement with previous reports on adults (Oddsson and Westing 1991; Ostenberg et al. 1998; Paasuke et al. 2001). This is explicable by the fact that, by their nature, all jumps must attain considerable takeoff velocities for the body to leave the ground. Angular knee velocities at jump takeoffs have been shown to resemble or exceed the angular velocity employed in our dynamic knee extension testing (240\%s), (e.g., (Bosco and Komi 1979)). Thus, our findings extend to young athletes the relationship between jumping performance vs. dynamic pT and pRTD, previously observed in adults. The findings highlight, however, that jumping performance is better related to contractile variables ( $\mathrm{pT}, \mathrm{pRTD}, \mathrm{Q}_{30}$ ) measured during dynamic contractions, rather than during isometric contractions.

A second important finding is that only absolute dynamic $\mathrm{pT}$ and body mass were found to significantly account for the observed jump-height variance in the stepwise linear regression. pRTD, which on its own was a moderately robust predictor (Table 3), did not add to the cumulative predictive power, likely due to its high co-linearity with pT $(\mathrm{r}=0.89)$.

Correspondingly, $\mathrm{Q}_{30}$, typically associated with contractile explosiveness, was only weakly correlated with jump height and that, only in SJ and DJ. The reason for these seemingly counterintuitive findings likely lies in the fact that both variables, $\mathrm{Q}_{30}$ and $\mathrm{pRTD}$, affect or reflect mainly the initial part of a contraction, isometric or dynamic. However, since at takeoff, both angular and linear velocities are quite high (Bosco and Komi 1979), it is the dynamic pT (for which pRTD and $\mathrm{Q}_{30}$ are only secondary correlates) and the mass it must accelerate that ultimately determine jump height.

To the best of our knowledge, the present study is the first to examine the relationship of both isometric and dynamic pT and pRTD with jump performance in youth. In adults, an early study by Häkkinen et al. (Hakkinen 1991) reported a strong correlation $(\mathrm{r}=0.81)$ between 
isometric $\mathrm{pT}$ and jump performance in a sample of male and female athletes. However, later studies reported no such relationships (Anderson et al. 1991; de Ruiter et al. 2007; de Ruiter et al. 2006). The heterogeneous nature of Häkkinen's participants (Hakkinen 1991) may have contributed to a wide range of $\mathrm{pT}$ and jump heights, resulting in a high correlation between the two. Additionally, while dynamic rather than isometric force is a dominant determinant of jump height, there is nevertheless a strong correlation between the two ( $\mathrm{r}=0.76$ in our group), which explains how isometric $\mathrm{pT}$ can be a factor in a heterogeneous group. However, in a relatively homogenous group of adults, as in our young athletes, maximal isometric strength does not appear to significantly factor in predicting jump performance (Wilson and Murphy 1996).

It is noteworthy that isometric pRTD was found to correlate with jump height (de Ruiter et al. 2006; Paasuke et al. 2001) in adult recreational athletes, but not among competitive athletes, (Baker et al. 1994; de Ruiter et al. 2007; McGuigan and Winchester 2008). The degree of specialization and consequent differentiation between the isometric and dynamic force-generation capacities is presumably lower among untrained or recreationally-active individuals compared with well-trained athletes, likely due to the volume and specificity of their training. Thus, the fact that isometric pRTD did not correlate with jump performance in our young athletes, is likely due to both their relative homogeneity as soccer players and the acquired specialization derived from their training. Our findings therefore extend to young athletes what has previously been demonstrated in adult athletes.

Surprisingly, no single, non-normalized variable individually accounted for more than $\sim 12 \%(\mathrm{r}=0.35)$ of the observed variance in any of the jumps (Table 3$)$. The step-wise regression analysis (Table 4) was used to elucidate the major determinants of jump performance. It was found, however, that only body mass $(\mathrm{r}=0.22-0.31)$ and dynamic $\mathrm{pT}(\mathrm{r}=0.13-0.35)$ demonstrated 
statistically-significant contributions to jump-height prediction and that the combined predictive power of all measured variables could not account for more than $~ 44 \%$ of the observed variance in CMJ jump height (32 and 24\% in SJ and DJ, respectively; Table 4). Thus, although dynamic contractile measures, as used in our and other studies, are better related to jumping performance than isometric ones, in young athletes they too do not sufficiently account for what takes place in an actual jump. A possible explanation is that the observed low predictive power of the commonly used, dynamometer-measured parameters is due to their low specificity with the nature of jumping. For example, dynamometer testing starts from a static, unloaded state, while all jumping contractions are variably dynamic and involve pre-loading by the supported body mass and its acceleration and by preceding counter movements. The situation is further confounded by the fact that all types of jumping involve a degree of pre-streching and thus, are also affected by the stretch reflex. This means that the dynamometer-measured parameters of $\mathrm{pT}, \mathrm{pRTD}$, and $\mathrm{Q}_{30}$ may not adequately resemble the corresponding paprameters relevant during a jump.

Another major unaccounted-for factor is that of skill. All jump types require varying degrees of coordinated timing of multi-jointed, multi-muscle contractions. Even balance, which may be regarded as a component of skill, has been shown closely related $\left(\mathrm{R}^{2}=0.37-0.70\right)$ to jumping performance (Hammami et al. 2016). However, none of the dynamometer-measured variables address the skill, or the additional muscles involved in jumping. The fact that CMJ was the most predictable of the three jumps, may be accounted for by the relative familiarity of most people, our participants included, with this type of jump.

The drop jump proved to be the least predictable of the three jumps (Table 4). In addition to jumping skill, DJ requires optimal timing of the jump, following ground contact. Mistiming 
could mean both missing out on the stretch-reflex boost inherent to plyometric-type activities, as well as sub-optimal knee and hip angles.

The rate of activation, as reflected by $\mathrm{Q}_{30}$, moderately correlated with SJ and DJ ( $\mathrm{r}=0.34$, 0.31, respectively), but not with CMJ height. A possible explanation for this difference is the shorter lag time between movement onset and actual takeoff in SJ and DJ. CMJ's longer lag time is due to the intervening counter movement, which is an important but confounding factor in CMJ's height prediction. CMJ's longer lag time moved the emphasis from the initial activation $\left(\mathrm{Q}_{30}\right)$ to the dynamic $\mathrm{pRTD}$ and $\mathrm{pT}$, which were indeed more related to CMJ performance than to that of SJ and DJ (Table 3).

A limitation of our study is the use of EMG recording from only one muscle. While the vastus lateralis is considered a prime mover in knee extension, it is possible that a composite EMG value including other prime movers could result in stronger correlations between neuromuscular attributes and jump performance (de Ruiter et al. 2007; de Ruiter et al. 2006). Additionally, the postural position of participants during the isometric and dynamic testing is different from that of jumping. It is possible that strength and neuromuscular attributes measured in an isometric thigh-pull test would result in higher correlations with jump performance.

In conclusion, our findings demonstrate that among young soccer players, fast dynamic, rather than isometric (static) measures (pT, $\mathrm{pRTD}, \mathrm{Q}_{30}$ ), are better related to jump performance. Still, the fact that even in conjunction, all those widely-used variables could not explain more than $24-44 \%$ of the observed jump-height variance, suggests that important determinants of jump capacity were not measured in the present, as well as previously reported studies. The discrepancy is likely due to the fact that the typically measured variables do not address skill or balance and do not capture the nature of muscular force application that is critical just prior to jump take-off. In 
laboratory testing, efforts should be directed at making testing tools and criteria more specific to the forces, kinetics, and joint angles relevant to jump take-offs. To this end, the use of force plates and goniometry rather than static and isokinetic dynamometers may better address testing specificity. 


\section{ACKNOWLEDGEMENTS}

First, the authors wish to thank all participants for the hard work and dedication they invested in this study. We are also indebted to the boys' parents or guardians for consenting, bringing the boys, and making it all possible. The authors would like to acknowledge Dr. Geoff Gamble and Paul Skiba from Niagara Health and Rehab Centre for providing some of the performance testing equipment. We would also like to thank Clayton Rosario and Elite Soccer Development for their assistance in participant recruitment. The study was funded by Brock University.

\section{Conflict of interest}

The authors have no conflict of interest to declare. 
Strength and jumping in young athletes

\section{REFERENCES}

Aagaard, P., Simonsen, E.B., Andersen, J.L., Magnusson, P., and Dyhre-Poulsen, P. 2002. Increased rate of force development and neural drive of human skeletal muscle following resistance training. J. Appl. Physiol. 93(4): 1318-1326. doi:

10.1152/japplphysiol.00283.2002

Anderson, M.A., Gieck, J.H., Perrin, D.H., Weltman, A., Rutt, R.A., and Denegar, C.R. 1991. The Relationships among Isometric, Isotonic, and Isokinetic Concentric and Eccentric Quadriceps and Hamstring Force and Three Components of Athletic Performance. J. Orthop. Sports Phys. Ther. 14(3): 114-120. doi: 10.2519/jospt.1991.14.3.114

Baker, D., Wilson, G., and Carlyon, B. 1994. Generality versus specificity: a comparison of dynamic and isometric measures of strength and speed-strength. Eur. J. Appl. Physiol. Occup. Physiol. 68(4): 350-355. PMID: 8055895

Blimkie, C.J. 1989. Age- and sex-associated variation in strength during childhood: Anthropometric, morphologic, neurologic, biomechanical, endocrinologic, genetic, and physical activity correlates. In Perspectives in Exercise Science and Sports Medicine, Vol. 2: Youth, Exercise and Sports. Edited by C.V. Gisolfi. Benchmark Press, Indianapolis, IN. pp. 99-163.

Bobbert, M.F., Huijing, P.A., and van Ingen Schenau, G.J. 1987. Drop jumping. I. The influence of jumping technique on the biomechanics of jumping. Med. Sci. Sports Exerc. 19(4): 332-338. PMID: 3657481

Bobbert, M.F., Gerritsen, K.G., Litjens, M.C., and Van Soest, A.J. 1996. Why is countermovement jump height greater than squat jump height? Med. Sci. Sports Exerc. 28(11): 1402-1412. PMID: 8933491 
Bosco, C. and Komi, P.V. 1979. Potentiation of the mechanical behavior of the human skeletal muscle through prestretching. Acta Physiol. Scand. 106(4): 467-472. doi: 10.1111/j.17481716.1979.tb06427.x

Cohen, R., Mitchell, C., Dotan, R., Gabriel, D., Klentrou, P., and Falk, B. 2010. Do neuromuscular adaptations occur in endurance-trained boys and men? Applied physiology, nutrition, and metabolism = Physiologie appliquee, nutrition et metabolisme. 35(4): 471479. doi: 10.1139/h10-031

de Ruiter, C.J., Kooistra, R.D., Paalman, M.I., and de Haan, A. 2004. Initial phase of maximal voluntary and electrically stimulated knee extension torque development at different knee angles. J. Appl. Physiol. (1985). 97(5): 1693-1701. doi: 10.1152/japplphysiol.00230.2004 de Ruiter, C.J., Vermeulen, G., Toussaint, H.M., and de Haan, A. 2007. Isometric knee-extensor torque development and jump height in volleyball players. Med. Sci. Sports Exerc. 39(8): 1336-1346. doi: 10.1097/mss.0b013e318063c719

de Ruiter, C.J., de Korte, A., Schreven, S., and de Haan, A. 2010. Leg dominancy in relation to fast isometric torque production and squat jump height. Eur. J. Appl. Physiol. 108(2): 247255. doi: 10.1007/s00421-009-1209-0

de Ruiter, C.J., Van Leeuwen, D., Heijblom, A., Bobbert, M.F., and de Haan, A. 2006. Fast unilateral isometric knee extension torque development and bilateral jump height. Med. Sci. Sports Exerc. 38(10): 1843-1852. DOI: 10.1249/01.mss.0000227644.14102.50 Dotan, R., Mitchell, C., Cohen, R., Klentrou, P., Gabriel, D., and Falk, B. 2012. Child-adult differences in muscle activation - a review. Pediatr. Exerc. Sci. 24(1): 2-21. PMID: 22433260

Falk, B., Usselman, C., Dotan, R., Brunton, L., Klentrou, P., Shaw, J., et al. 2009. Child-adult differences in muscle strength and activation pattern during isometric elbow flexion and 
extension. Applied physiology, nutrition, and metabolism = Physiologie appliquee, nutrition et metabolisme. 34(4): 609-615. DOI: 10.1139/H09-020

Gabriel, D.A. and Boucher, J.P. 2000. Practicing a maximal performance task: a cooperative strategy for muscle activity. Res. Q. Exerc. Sport. 71(3): 217-228. DOI: $10.1080 / 02701367.2000 .10608902$

Glatthorn, J.F., Gouge, S., Nussbaumer, S., Stauffacher, S., Impellizzeri, F.M., and Maffiuletti, N.A. 2011. Validity and reliability of Optojump photoelectric cells for estimating vertical jump height. Journal of strength and conditioning research / National Strength \& Conditioning Association. 25(2): 556-560. doi: 10.1519/JSC.0b013e3181ccb18d

Gore, C.J. (2000). Physiological Tests for Elite Athletes. Champaign, IL: Human Kinetics.

Hakkinen, K. 1991. Force production characteristics of leg extensor, trunk flexor and extensor muscles in male and female basketball players. J. Sports Med. Phys. Fitness. 31(3): 325331. PMID: 1798300

Hammami, R., Chaouachi, A., Makhlouf, I., Granacher, U., and Behm, D.G. 2016. Associations Between Balance and Muscle Strength, Power Performance in Male Youth Athletes of Different Maturity Status. Pediatr Exerc Sci. 28(4): 521-534. doi: 10.1123/pes.2015-0231

Hodges, P.W. and Bui, B.H. 1996. A comparison of computer-based methods for the determination of onset of muscle contraction using electromyography. Electroencephalogr. Clin. Neurophysiol. 101(6): 511-519. PMID: 9020824

Kraska, J.M., Ramsey, M.W., Haff, G.G., Fethke, N., Sands, W.A., Stone, M.E., et al. 2009. Relationship between strength characteristics and unweighted and weighted vertical jump height. International journal of sports physiology and performance. 4(4): 461-473. PMID: 20029097 
Kriemler, S., Puder, J., Zahner, L., Roth, R., Braun-Fahrlander, C., and Bedogni, G. 2009. Crossvalidation of bioelectrical impedance analysis for the assessment of body composition in a representative sample of 6- to 13-year-old children. Eur. J. Clin. Nutr. 63(5): 619-626. doi: 10.1038/ejen.2008.19

McGuigan, M.R. and Winchester, J.B. 2008. The relationship between isometric and dynamic strength in college football players. Journal of sports science \& medicine. 7(1): 101-105. PMCID: 3763333

Mirwald, R.L., Baxter-Jones, A.D., Bailey, D.A., and Beunen, G.P. 2002. An assessment of maturity from anthropometric measurements. Med. Sci. Sports Exerc. 34(4): 689-694. PMID: 11932580

Mitchell, C., Cohen, R., Dotan, R., Gabriel, D., Klentrou, P., and Falk, B. 2011. Rate of muscle activation in power- and endurance-trained boys. International journal of sports physiology and performance. 6(1): 94-105. PMID: 21487153

Nuzzo, J.L., McBride, J.M., Cormie, P., and McCaulley, G.O. 2008. Relationship between countermovement jump performance and multijoint isometric and dynamic tests of strength. Journal of strength and conditioning research / National Strength \& Conditioning Association. 22(3): 699-707. doi: 10.1519/JSC.0b013e31816d5eda

Oddsson, L. and Westing, S.H. 1991. Jumping height can be accurately predicted from selected measurements of muscle strength and biomechanical parameters. Biomechanics in Sports. 9(29-33.

Ostenberg, A., Roos, E., Ekdahl, C., and Roos, H. 1998. Isokinetic knee extensor strength and functional performance in healthy female soccer players. Scand. J. Med. Sci. Sports. 8(5 Pt 1): 257-264. PMID: 9809383 
Paasuke, M., Ereline, J., and Gapeyeva, H. 2001. Knee extension strength and vertical jumping performance in nordic combined athletes. J. Sports Med. Phys. Fitness. 41(3): 354-361. PMID: 11533567

Peterson, M.D., Alvar, B.A., and Rhea, M.R. 2006. The contribution of maximal force production to explosive movement among young collegiate athletes. Journal of strength and conditioning research / National Strength \& Conditioning Association. 20(4): 867-873. doi: 10.1519/R-18695.1

Sale, D.G., Spriet, L.L. 1996. Skeletal muscle function and energy metabolism. In Exercise and the Female - A Life Span Approach. Edited by D.R.L. O. Bar-Or, P.M. Clarkson Cooper Publishing Group, Carmel, IN. pp. 289-359.

Tanner, J.M. (1962). Growth at Adolescence. Oxford: Blackwell Scientific Publications. Thompson, B.J., Ryan, E.D., Sobolewski, E.J., Smith, D.B., Akehi, K., Conchola, E.C., et al. 2013. Relationships between rapid isometric torque characteristics and vertical jump performance in division I collegiate American football players: influence of body mass normalization. Journal of strength and conditioning research / National Strength \& Conditioning Association. 27(10): 2737-2742. doi: 10.1519/JSC.0b013e318281637b

Waugh, C.M., Korff, T., Fath, F., and Blazevich, A.J. 2013. Rapid force production in children and adults: mechanical and neural contributions. Med. Sci. Sports Exerc. 45(4): 762-771. doi: 10.1249/MSS.0b013e31827a67ba

Wilson, G.J. and Murphy, A.J. 1996. The use of isometric tests of muscular function in athletic assessment. Sports Med. 22(1): 19-37. PMID: 8819238 
Table 1 - Participants' physical characteristics $(n=41)$

\begin{tabular}{|l|l|c|c|}
\hline \multicolumn{2}{|l|}{} & Mean \pm SD & Range \\
\hline \multirow{2}{*}{ Age } & years & $\mathbf{1 2 . 6} \pm 0.6$ & $\mathbf{1 1 . 4 - 1 3 . 9}$ \\
\hline \multirow{2}{*}{ Maturation } & years to PHV & $-\mathbf{1 . 4 0} \pm 0.57$ & $-\mathbf{2 . 5 2}-\mathbf{0 . 5 2}$ \\
\cline { 2 - 4 } & Tanner stage frequency* & $\mathbf{3 , 8 , 1 2 , 1 0 , 5}$ & - \\
\hline Height & cm & $\mathbf{1 5 5 . 0} \pm 8.2$ & $\mathbf{1 3 8 . 0}-\mathbf{1 7 8 . 3}$ \\
\hline Body mass & $\mathrm{kg}$ & $\mathbf{4 4 . 3} \pm 8.3$ & $\mathbf{3 4 . 2}-\mathbf{6 3 . 4}$ \\
\hline Body Fat & $\%$ & $\mathbf{1 3 . 1} \pm 5.4$ & $\mathbf{4 . 4}-\mathbf{2 7 . 3}$ \\
\hline \multirow{2}{*}{ Training History } & years & $\mathbf{5 . 2} \pm 2.1$ & $\mathbf{1 - 9}$ \\
\cline { 2 - 4 } & Sessions $\cdot \mathrm{wk}^{-1}$ & $\mathbf{3 . 6} \pm 0.7$ & $\mathbf{2}-\mathbf{5}$ \\
\hline
\end{tabular}

* Number of boys in stages $1,2,3,4,5$, respectively. That is, three boys were in stage 1 , eight boys in stage 2, etc. Data for 3 boys could not be obtained. 
Table 2 - Participants' strength data (means \pm SDs)

\section{Peak Torque}

Absolute, $\mathrm{Nm}$

Relative, $\mathrm{Nm}^{\mathrm{kg}}{ }^{-1}$

Peak Rate of Torque Development

Absolute, $\mathrm{Nm}^{-1} \mathrm{~s}^{-1}$

Relative, $\mathrm{Nm}^{-1} \mathrm{~kg}^{-1}$
Isometric
$637.6 \pm 236.2$

$15.1 \pm 4.1$
Dynamic

$139.7 \pm 37.0$

$3.1 \pm 0.6$

$65.8 \pm 17.1$

$1.5 \pm 0.2$

$413.1 \pm 102.4$

$9.4 \pm 2.0$ 
Table 3 - Correlations of peak torque, peak rate of torque development, $\mathrm{Q}_{30}$, and body mass vs. jump performances.

\begin{tabular}{|c|c|c|c|c|c|c|c|}
\hline & \multirow{2}{*}{ Variable } & \multicolumn{2}{|c|}{ CMJ } & \multicolumn{2}{|c|}{ SJ } & \multicolumn{2}{|c|}{ DJ } \\
\hline & & $\mathbf{r}$ & $\mathbf{p}$ & $\mathbf{r}$ & $\mathbf{p}$ & $\mathbf{r}$ & $\mathbf{p}$ \\
\hline \multirow{6}{*}{ pT } & Absolute & & & & & & \\
\hline & - Isometric & 0.07 & 0.64 & -0.03 & 0.81 & -0.07 & 0.64 \\
\hline & - Dynamic & 0.35 & 0.02 & 0.13 & 0.41 & 0.16 & 0.29 \\
\hline & Body-mass normalized & & & & & & \\
\hline & - Isometric & 0.25 & 0.11 & 0.22 & 0.16 & 0.07 & 0.62 \\
\hline & - Dynamic & 0.66 & 0.0001 & $\mathbf{0 . 5 0}$ & 0.001 & 0.45 & 0.003 \\
\hline \multirow{6}{*}{ pRTD } & Absolute & & & & & & \\
\hline & - Isometric & 0.13 & 0.39 & -0.01 & 0.91 & 0.04 & 0.77 \\
\hline & - Dynamic & 0.35 & 0.02 & 0.12 & 0.43 & 0.16 & 0.30 \\
\hline & Body-mass normalized & & & & & & \\
\hline & - Isometric & 0.28 & 0.06 & 0.19 & 0.22 & 0.21 & 0.19 \\
\hline & - Dynamic & 0.56 & 0.0001 & 0.40 & 0.009 & 0.38 & 0.01 \\
\hline \multirow{2}{*}{$\mathbf{Q}_{30}$} & - Isometric & 0.27 & 0.09 & 0.18 & 0.24 & 0.16 & 0.30 \\
\hline & - Dynamic & 0.23 & 0.14 & $\mathbf{0 . 3 4}$ & 0.03 & 0.31 & 0.04 \\
\hline \multicolumn{2}{|c|}{ Body Mass } & -0.21 & 0.19 & -0.31 & 0.05 & -0.22 & 0.17 \\
\hline
\end{tabular}

$\mathrm{pT}=$ Peak Torque, $\mathrm{pRTD}=$ Peak rate of torque development, $\mathrm{Q}_{30}=$ Initial 30ms of EMG rise $\mathrm{CMJ}=$ Countermovement jump, $\mathrm{SJ}=$ Squat jump, $\mathrm{DJ}=$ Drop jump

Statistically-significant correlations in Bold 
Table 4 - Single and step-wise regression analysis between jump performance and dynamic peak torque, peak rate of torque development, $\mathrm{Q}_{30}$, body mass, and maturity

\begin{tabular}{|c|c|c|c|c|c|c|c|c|}
\hline & \multirow{2}{*}{ Predictor } & \multirow{2}{*}{$\begin{array}{c}\text { Pairwise } \\
\mathbf{R}^{2}\end{array}$} & \multicolumn{3}{|c|}{ Regression Coefficients } & \multirow[b]{2}{*}{$\mathbf{R}^{2}$} & \multirow[b]{2}{*}{ Adj. $\mathbf{R}^{2}$} & \multirow[b]{2}{*}{$\mathbf{p}$} \\
\hline & & & $\beta$ & Std. $\boldsymbol{\beta}^{*}$ & $\mathbf{p}$ & & & \\
\hline \multirow{5}{*}{ CMJ } & pT & 0.118 & 0.25 & 0.98 & 0.0001 & \multirow{5}{*}{0.444} & \multirow{5}{*}{0.365} & \multirow{5}{*}{0.001} \\
\hline & pRTD & 0.117 & -0.007 & -0.17 & 0.56 & & & \\
\hline & $\mathbf{Q}_{30}$ & 0.054 & -1375 & -0.09 & 0.53 & & & \\
\hline & Body Mass & 0.046 & -0.47 & -0.91 & 0.001 & & & \\
\hline & Maturity Offset & 0.005 & 1.21 & 0.16 & 0.44 & & & \\
\hline \multirow{5}{*}{ SJ } & $\mathbf{p T}$ & 0.020 & 0.22 & 0.81 & 0.03 & \multirow{5}{*}{0.317} & \multirow{5}{*}{0.220} & \multirow{5}{*}{0.01} \\
\hline & pRTD & 0.018 & -0.01 & -0.30 & 0.35 & & & \\
\hline & $\mathbf{Q}_{30}$ & 0.113 & 1541 & 0.09 & 0.56 & & & \\
\hline & Body Mass & 0.098 & -0.41 & -0.73 & 0.01 & & & \\
\hline & Maturity Offset & 0.027 & 0.89 & 0.11 & 0.63 & & & \\
\hline \multirow{5}{*}{ DJ } & pT & 0.030 & 0.20 & 0.67 & 0.09 & \multirow{5}{*}{0.238} & \multirow{5}{*}{0.129} & \multirow{5}{*}{0.07} \\
\hline & pRTD & 0.028 & -0.012 & -0.23 & 0.50 & & & \\
\hline & $\mathbf{Q}_{30}$ & 0.099 & 1999 & 0.11 & 0.52 & & & \\
\hline & Body Mass & 0.046 & -0.39 & -0.63 & 0.04 & & & \\
\hline & Maturity Offset & 0.003 & 1.69 & 0.18 & 0.44 & & & \\
\hline
\end{tabular}

$\mathrm{pT}=$ Peak Torque, $\mathrm{pRTD}=$ Peak rate of torque development, $\mathrm{Q}_{30}=$ Initial 30ms of EMG rise $\mathrm{CMJ}=$ Countermovement jump, $\mathrm{SJ}=$ Squat jump, DJ = Drop jump

Absolute pT and pRTD values were used for analysis

* - Standardized $\beta$ coefficient 


\section{Figure Legends}

Figure 1: Correlation between body-mass-normalized dynamic peak rate of torque development and counter-movement jump (a); squat jump (b), and drop jump (c). All correlations were statistically significant $(\mathrm{p}<0.05)$.

Figure 2: Correlation between body-mass-normalized dynamic peak rate of torque development and the rate of EMG rise $(\mathrm{p}<0.05)$. 
Figure 1

a

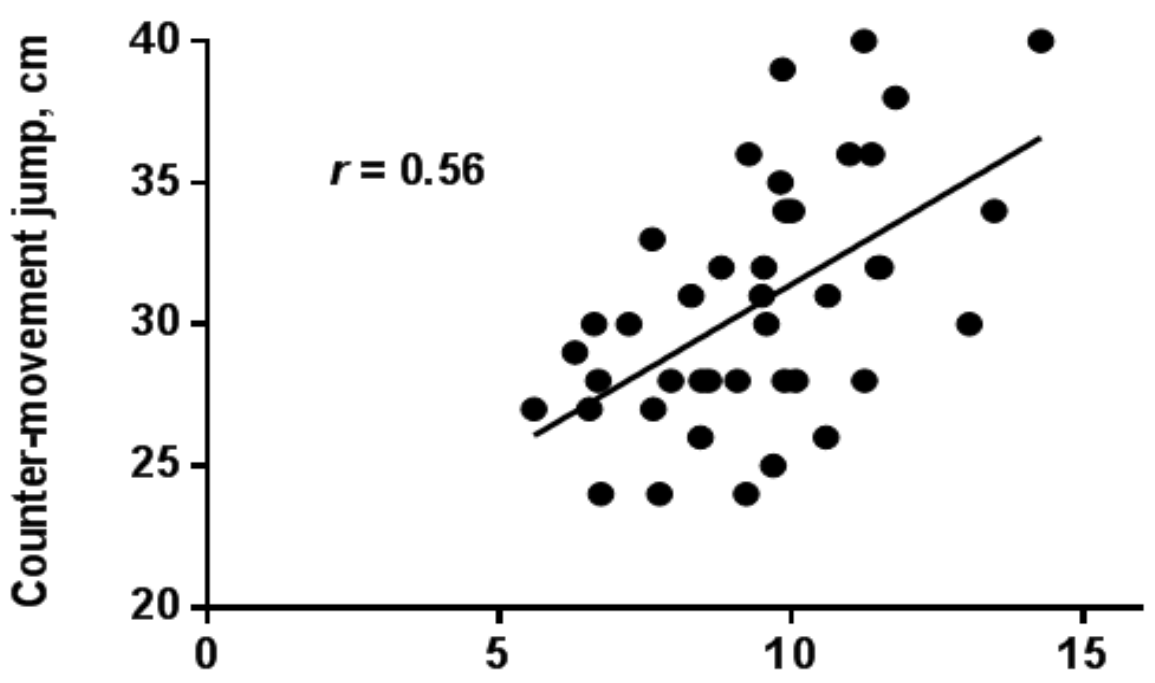

b

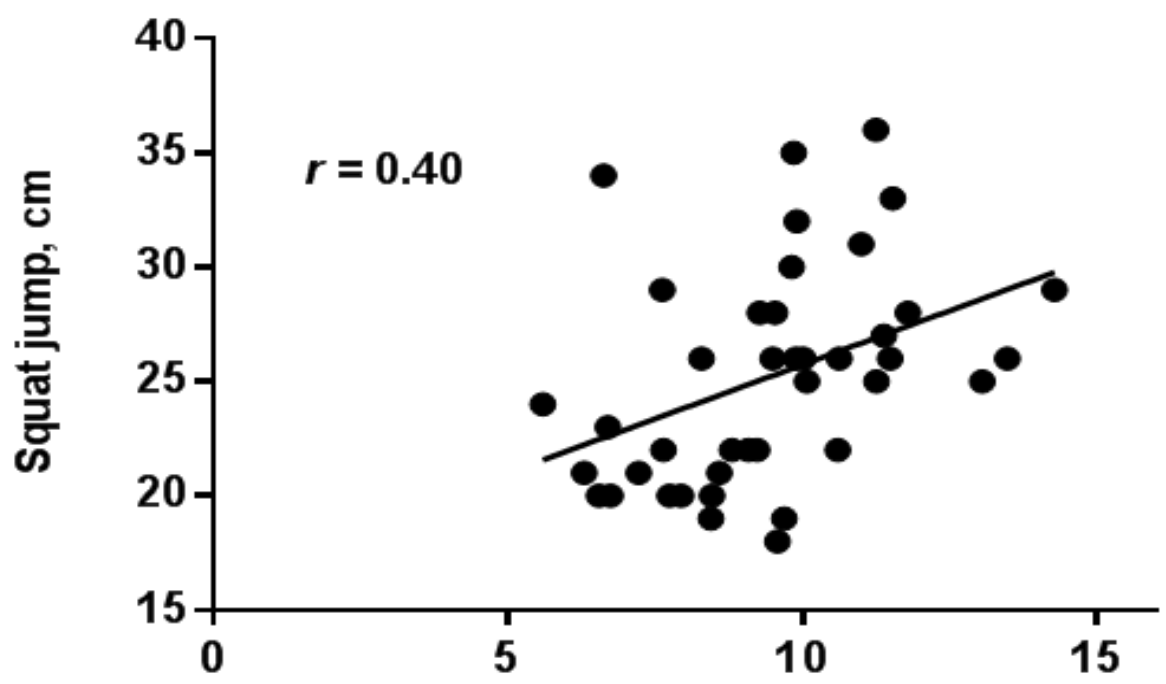

C

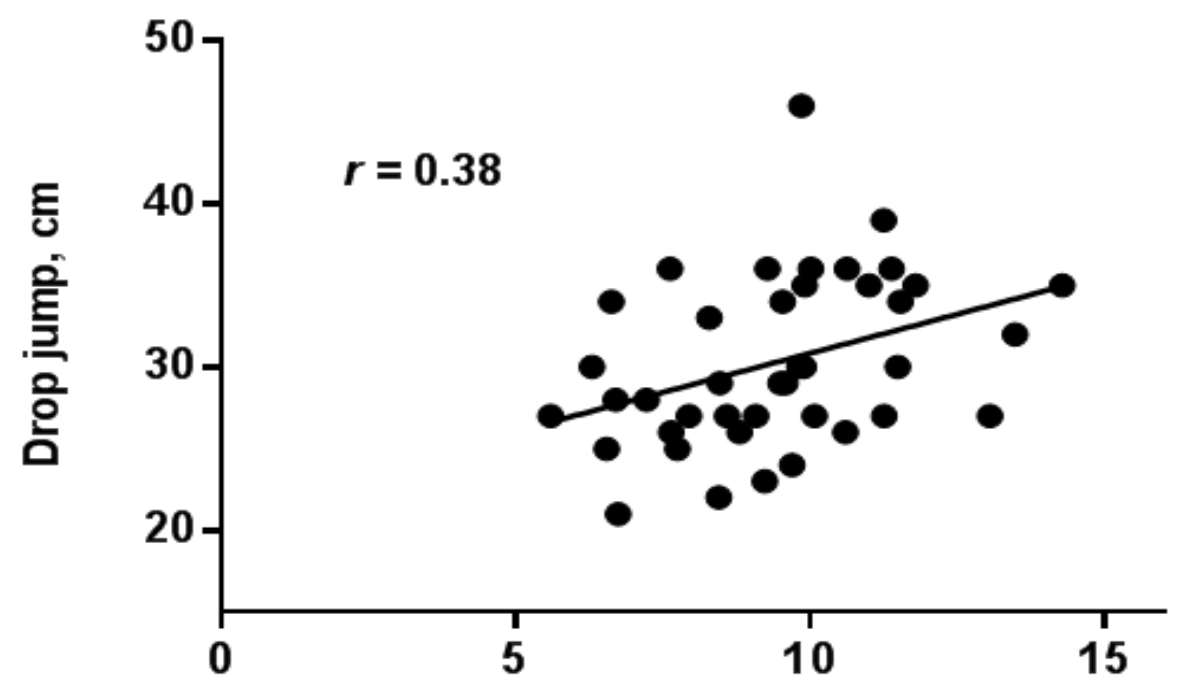

Peak rate of torque development, Nm.s ${ }^{-1} \cdot \mathrm{kg}^{-1}$ 


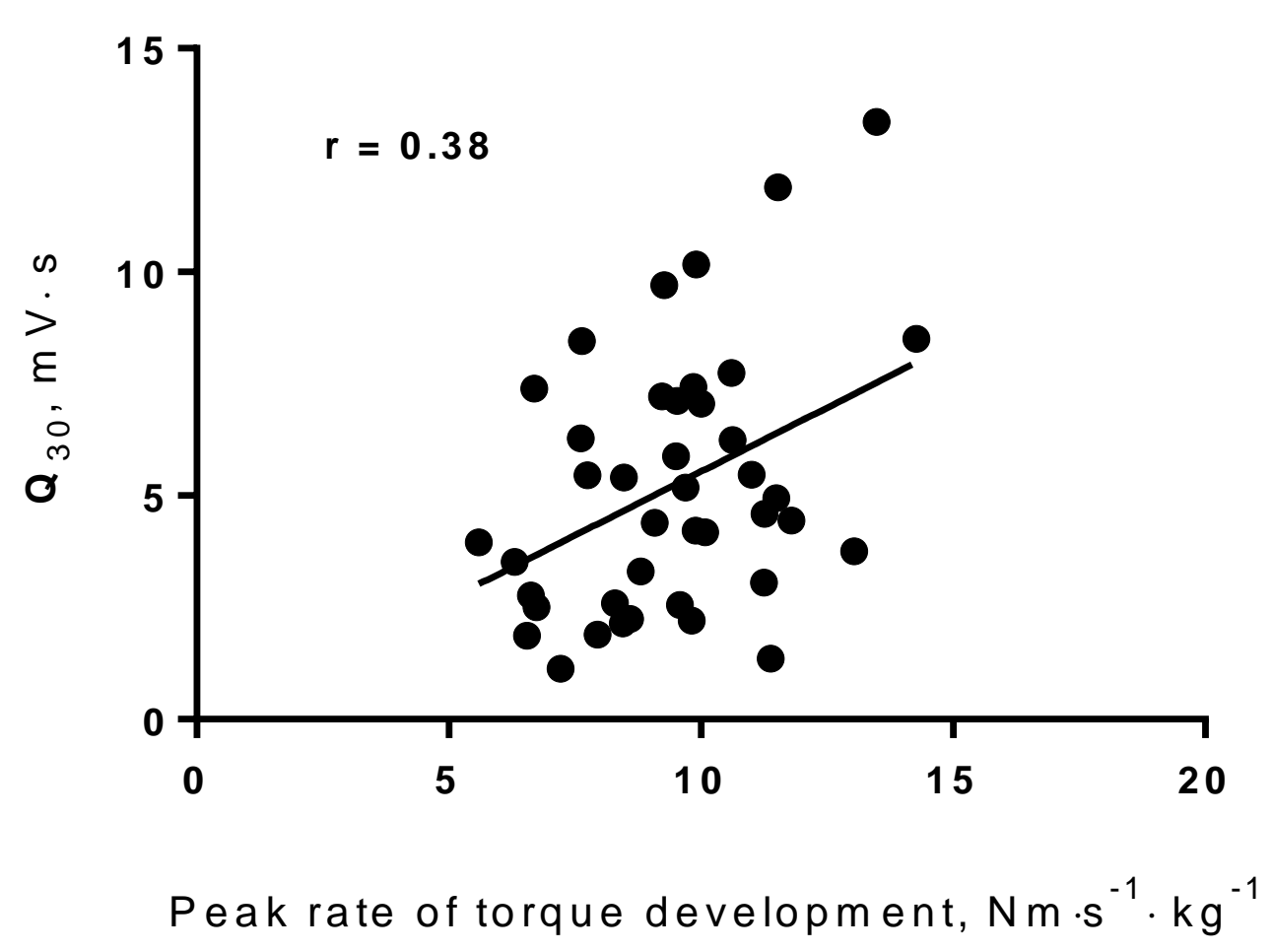

